\section{Rapid MRI of the lungs in children with pulmonary infections}

RM pulmonar rápida em crianças com infecções pulmonares

\section{Dear Editor,}

We read with interest the review article entitled "Chest magnetic resonance imaging: a protocol suggestion" by Hochhegger et al. ${ }^{(1)}$. The authors have reviewed the technical aspects and suggested a protocol for performing chest MRI. The authors have also described three major clinical indications for MRI of the lungs: staging of lung tumors; evaluation of pulmonary vascular diseases; and investigation of pulmonary abnormalities in patients who should not be exposed to radiation. Radiation exposure is particularly more serious in children, as they are at a greater risk of experiencing harmful effects from radiation compared to adults ${ }^{(2)}$.

In our recent prospective study in 26 children with leukemia presenting with febrile neutropenia ${ }^{(3)}$, we evaluated role of rapid lung MRI in the detection of nodules, consolidation and ground glass opacity (GGO) in this population. The duration of all the four sequences combined in our study was less than 2 minutes. The findings of HRCT and MRI were compared, with HRCT as the standard of reference. No significant difference was observed between the two modalities by the McNemar test $(\mathrm{p}>0.05)$. For the detection of nodules and consolidation by MRI, per-patient sensitivity, specificity, positive predictive value (PPV) and negative predictive value (NPV) were all $100 \%$. For the detection of GGO by MRI, per-patient sensitivity, specificity, PPV and NPV were $66.67 \%, 100 \%, 100 \%$ and $90.91 \%$, respectively. The kappa test showed perfect agreement between MRI and CT scan for the detection of nodules and consolidation $(\kappa=1)$, and a substantial agreement in the detection of GGO by MRI and CT scan $(\kappa=0.755)$. The results of our study indicated that pulmonary MRI has great potential as a diagnostic modality for the detection of lung parenchymal findings in patients with febrile neutropenia.

Similarly, we determined the diagnostic utility of rapid lung MRI for the detection of various pulmonary and mediastinal ab- normalities in 75 children with suspected pulmonary infections ${ }^{(4)}$. MRI demonstrated sensitivity, specificity, PPV, and NPV of $100 \%$ for detecting pulmonary consolidation, nodules (>3 mm), cyst/ cavity, hyperinflation, pleural effusion, and lymph nodes. The kappa test showed almost perfect agreement between MRI and MDCT in detecting thoracic abnormalities $(\kappa=0.965)$. No statistically significant difference was observed between MRI and MDCT for detecting thoracic abnormalities by the McNemar test $(\mathrm{p}=0.125)$.

As MRI does not have any radiation risks, it can be repeated to assess disease progression or regression without exposing the patients to radiation (as against performing the CT scan). We propose rapid lung MRI may also be used as an initial radiological investigation in patients with suspected pulmonary infections especially where repeated follow up imaging is required.

\section{REFERENCES}

1. Hochhegger B, Souza VVS, Marchiori E, et al. Chest magnetic resonance imaging: a protocol suggestion. Radiol Bras. 2015;48:373-80.

2. Sodhi KS, Lee EY. What all physicians should know about the potential radiation risk that computed tomography poses for paediatric patients. Acta Paediatr. 2014;103:807-11.

3. Sodhi KS, Khandelwal N, Saxena AK, et al. Rapid lung MRI - paradigm shift in evaluation of febrile neutropenia in children with leukemia: a pilot study. Leuk Lymphoma. 2016;57:70-5.

4. Sodhi KS, Khandelwal N, Saxena AK, et al. Rapid lung MRI in children with pulmonary infections: time to change our diagnostic algorithms. J Magn Reson Imaging. 2015 Nov 6. doi:10.1002/jmri.25082. [Epub ahead of print].

Kushaljit Singh Sodhi ${ }^{1}$, Anmol Bhatia ${ }^{2}$, Niranjan Khandelwal ${ }^{1}$

1. Department of Radiodiagnosis and Imaging, Post Graduate Institute of Medical Education and Research, Sector-12, Chandigarh 160012, India. 2. GE Radiology Section, Department of Gastroenterology, Post Graduate Institute of Medical Education and Research, Sector-12, Chandigarh 160012 India. Mailing Address: Dr. Anmol Bhatia. Assistant Professor, MD, GE Radiology Section, Department of Gastroenterology, Post Graduate Institute of Medical Education and Research (PGIMER), Chandigarh, India. Email: anmol_bhatia26@yahoo.co.in.

http://dx.doi.org/10.1590/0100-3984.2016.0025

\section{Incidental diagnosis of struma ovarii through radioiodine whole- body scanning: incremental role of SPECT/CT}

Contribuição da SPECT/CT no diagnóstico incidental de struma ovarii em pesquisa de corpo inteiro com iodo-131

Dear Editor,

A 76-year-old woman with papillary thyroid cancer (staging: pT3pNlpMx) was referred for radioiodine (I-131) therapy after total thyroidectomy. The thyroglobulin titer was elevated (190 ng/ $\mathrm{mL}$ ) and thyroid stimulating hormone (TSH) levels remained suppressed despite thyroxine withdrawal. A radioiodine whole-body scan (WBS) evinced an area of intense pelvic uptake (Figure 1A), which corresponded to a heterogeneous pelvic mass posteriorly to uterus on fused single-photon emission computed tomography/ computed tomography (SPECT/CT) images (Figure 1B). The SPECT/CT findings suggested a diagnosis of struma ovarii. Complementary pelvic magnetic resonance imaging depicted a lobulated multicystic pelvic mass with a solid component, probably originating from the left ovary (Figures $1 \mathrm{C}$ and 1D). Total hysterectomy was performed, revealing a mature teratoma with thyroid tissue (struma ovarii). Five months after surgical resec- tion, the patient was treated with $7400 \mathrm{MBq}(200 \mathrm{mCi})$ of I-131. A post-treatment radioiodine WBS evinced a cervical thyroidal remnant and a focal area of increased radioiodine uptake in the proximal diaphysis of the left femur, with no matching alteration on CT images (not shown). The TSH-stimulated thyroglobulin titer was $2.4 \mathrm{ng} / \mathrm{mL}$ (normal value, $<35.0 \mathrm{ng} / \mathrm{mL}$ ). At month 3 of clinical follow-up, the patient had not presented any symptoms concerning the left lower limb and the thyroglobulin titer remained at a normal range.

Images obtained in a radioiodine WBS are noisy and have low spatial resolution. It is therefore often difficult to do proper anatomical localization, basically due to the high-energy characteristics of radioiodine ${ }^{(1)}$. At our institution, we often resort to SPECT/CT to further evaluate cases with inconclusive findings on standard planar scintigraphic images. The role of SPECT/CT for the evaluation of patients with well-differentiated thyroid carcinoma has not yet been established, although a few studies have demonstrated its superiority in the localization and identification of metastatic lesions ${ }^{(2,3)}$. In the case presented here, we believe that SPECT/CT played an important role in the correct anatomical location of the pelvic focal uptake, as well as improving the 


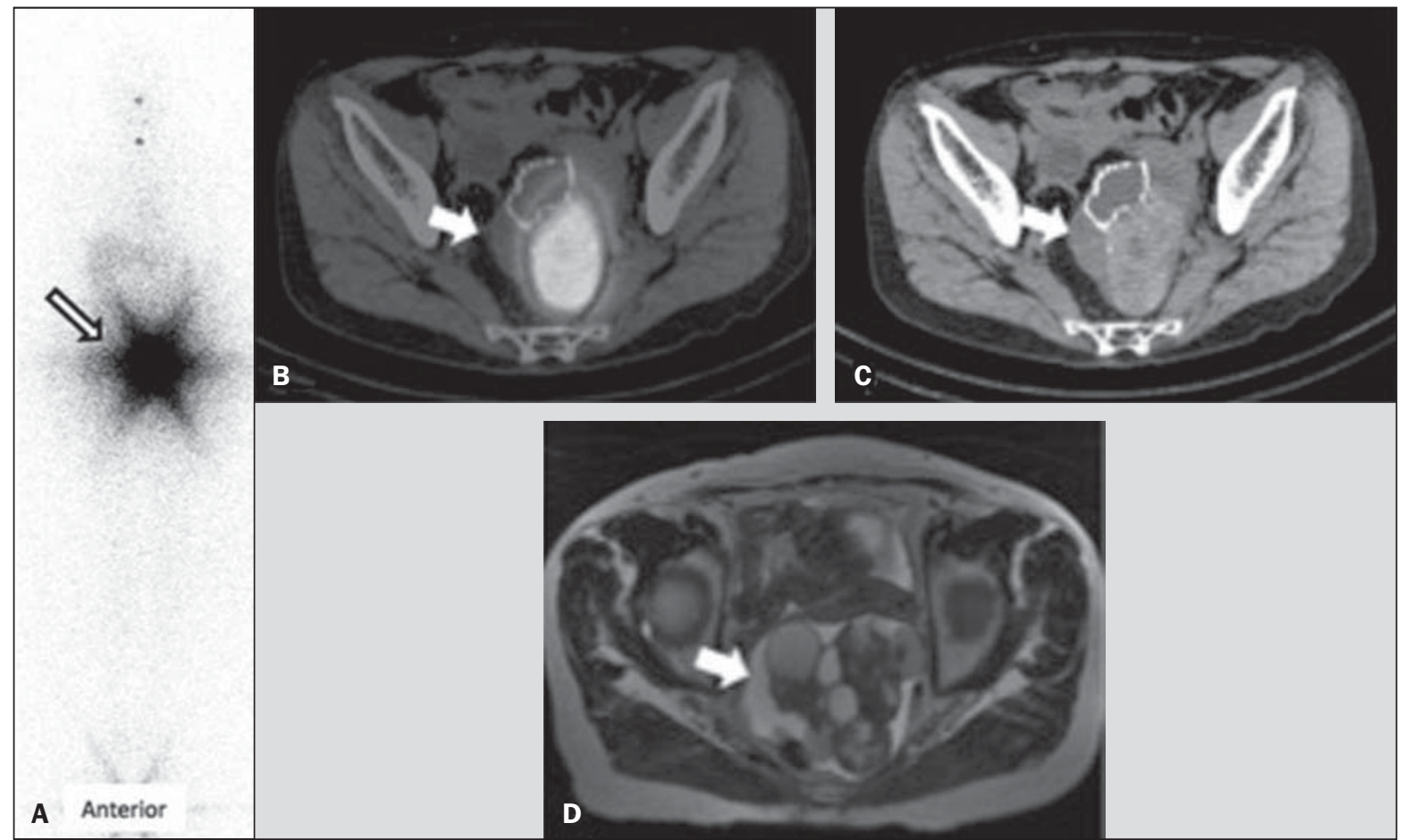

Figure 1. A: Anterior view of pre-treatment radioiodine whole-body scan showing an area of intense pelvic uptake (arrow). B: Fused SPECT/CT images. C: CT image. The arrows indicate a heterogeneous pelvic mass located posterior to the uterus. D: Axial T2-weighted magnetic resonance imaging scan. The arrow indicates a lobulated multicystic pelvic mass with a solid component.

differential diagnosis by adding tomographic features that supported the hypothesis of struma ovarii ${ }^{(4,5)}$.

Surgical resection is the mainstay of struma ovarii treatment $^{(6,7)}$, and it is recommended that patients be closely monitored through sequential thyroglobulin measurements, along with radioiodine WBS if recurrence is suspected, during follow-up. For malignant struma ovarii, a longer follow-up period is recommended, usually more than 10 years. Adjuvant I-131 therapy (after total thyroidectomy) might be considered in some patients ${ }^{(6)}$. In our case, post-treatment radioiodine WBS evinced a focal area of radioiodine uptake in the proximal left femur, probably due to benign and nonspecific etiology rather than metastatic disease, given that there were no matching anatomic alterations or symptoms. Subsequent follow-up will be needed in order to confirm that impression. In conclusion, fused SPECT/CT images played an important role in the differential diagnosis of a benign pelvic mass incidentally detected in a pre-treatment radioiodine WBS in a patient with papillary thyroid carcinoma.

\section{REFERENCES}

1. Salman WD, Singh M, Twaij Z. A case of papillary thyroid carcinoma in struma ovarii and review of the literature. Patholog Res Int. 2010;2010: 352476
2. Ikeuchi T, Koyama T, Tamai K, et al. CT and MR features of struma ovarii. Abdom Imaging. 2012;37:904-10.

3. Dujardin MI, Sekhri P, Turnbull LW. Struma ovarii: role of imaging? Insights Imaging. 2014;5:41-51.

4. Maruoka Y, Abe K, Baba S, et al. Incremental diagnostic value of SPECT/ CT with 131 I scintigraphy after radioiodine therapy in patients with welldifferentiated thyroid carcinoma. Radiology. 2012;265:902-9.

5. Billan S, Abdah-Bortnyak R, Cohen H, et al. Metastatic malignant struma ovarii. Isr Med Assoc J. 2011;13:247-8.

6. Choi B, Kim DH, Son SH, et al. Usefulness of SPECT/CT for equivocal findings on (131)I whole-body scan in a patient with differentiated papillary thyroid cancer. Clin Nucl Med. 2014;39:e160-2.

7. Agriantonis DJ, Hall L, Wilson MA. Pitfalls of I-131 whole body scan interpretation: bronchogenic cyst and mucinous cystadenoma. Clin Nucl Med. 2008;33:325-7.

Rômulo Hermeto Bueno do Vale ${ }^{1}$, Heitor Naoki Sado ${ }^{1}$, Débora Lucia Seguro Danilovic ${ }^{1}$, Pulo Schiavom Duarte ${ }^{1}$, Marcelo Tatit Sapienza ${ }^{1}$

1. Instituto do Câncer do Estado de São Paulo Octavio Frias de Oliveira (Icesp), São Paulo, SP, Brazil. Mailing Address: Dr. Heitor Naoki Sado. Centro de Medicina Nuclear - Icesp. Avenida Doutor Arnaldo, 251, 4SS, Consolação. São Paulo, SP, Brazil, 01246-000. E-mail: heitor.sado@ hc.fm.usp.br

http://dx.doi.org/10.1590/0100-3984.2015.0027

\section{Rim em panqueca com cistos e ureter único}

Pancake kidney with cysts and a single ureter

\section{Sr. Editor,}

Paciente masculino, 56 anos, foi encaminhado por cirurgião geral, após colecistectomia com anastomose biliodigestiva por coledocolitíase, para a realização de tomografia computadorizada (TC) no Hospital Universitário da Universidade Federal do Piauí, em razão de achado intraoperatório de massa pulsátil no abdome.
O paciente não tinha outras comorbidades e não tomava medicamentos.

$\mathrm{Na}$ TC de abdome com contraste identificou-se um rim em panqueca com cistos (Figura 1A) e imagem de reconstrução tridimensional da TC com contraste (fase excretora) revelou ureter único (Figura 1B). As imagens de corte axial e reconstrução coronal de TC de abdome (fase portal) mostraram massa única, achatada, mediana, não reniforme, na região da bifurcação aortoilíaca, caracterizando rim em panqueca (Figuras 1C e 1D). 